\title{
Utilizing Exhaust Valve Opening Modulation for Fast Warm-up of Exhaust After-treatment Systems on Highway Diesel Vehicles
}

\author{
Hasan Üstün Başaran ${ }^{*}$ \\ 0000-0002-1491-0465 \\ ${ }^{1}$ Naval Architecture and Marine Engineering Department, Faculty of Naval Architecture and Ocean Engineering, Izmir Katip Celebi \\ University, Izmir, 35620, Turkey
}

\begin{abstract}
Current on-road vehicles are generally outfitted with exhaust after-treatment (EAT) systems to meet the stringent emission regulations. At cold start and lowloaded operations, those systems need to be warmed up above a threshold temperature (generally $250^{\circ} \mathrm{C}$ ) for effective performance. High exhaust temperatures and high exhaust flow rates are required for fast EAT warm-up which are mostly not available at low-loaded operations. Therefore, the objective of this work is to improve EAT warm-up at low loads via exhaust valve opening (EVO) modulation which allows both elevated exhaust temperatures and exhaust flow rates.

A 1-D engine simulation program is used to model the system which is set to operate at 1200 RPM engine speed and at 2.5 bar brake mean effective pressure (BMEP) engine load. Exhaust temperature can be increased above $250^{\circ} \mathrm{C}$ via either early or late EVO timings. Reduced expansion work in advanced EVO timings and increased pumping loss (from 0.6 bar to 1.4 bar) in retarded EVO timings require higher fuel consumption (up to $15 \%$ and $20 \%$, respectively) to keep engine load constant. Those high fuel penalties reduce engine air-to-fuel ratio (up to $12 \%$ ) and rise exhaust temperature more than $55^{\circ} \mathrm{C}$. Exhaust mass flow rate is improved from $4.75 \mathrm{~kg} / \mathrm{min}$ to close to $5.2 \mathrm{~kg} / \mathrm{min}$ in the system as well. The method increases exhaust gas energy from $950 \mathrm{~kJ} / \mathrm{min}$ to close to 1350 $\mathrm{kJ} / \mathrm{min}$ and rises heat transfer rate to the EAT system up to $140 \%$ compared to nominal condition. The technique is highly effective at heating up EAT systems, however, it also causes high fuel inefficiency which needs to be considered.
\end{abstract}

Keywords: Exhaust after-treatment Warm-up; Thermal management; Exhaust gas temperature; Exhaust flow rate; Exhaust valve opening modulation
* Corresponding author

Hasan Üstün Başaran

hustun.basaran@ikc.edu.tr

Adress: Naval Architecture and Marine Engineering Department, Faculty of Naval Architecture and Ocean Engineering, Izmir Katip Celebi University, Izmir, Turkey

Tel:+902323293535 (office extension 4520)

Fax: +902323860888

Research Article

Manuscript

Received 25.12.2019

Revised 18.02.2020

Accepted 25.02.2020

Doi: 10.30939/ijastech..664860

\section{Introduction}

Modern automotive vehicles mostly utilize diesel engines thanks to their fuel-saving and cost-efficient performance. However, current emission norms on diesel engines are highly stringent and seem to be a major challenge for their prevalent use on highway vehicles. For instance, in the EU, criteria pollutants nitrogen oxides $\left(\mathrm{NO}_{\mathrm{x}}\right)$ and particulate matter (PM) for passenger cars with diesel engines are restricted to remain below $0.08 \mathrm{~g} / \mathrm{km}$ and $0.005 \mathrm{~g} / \mathrm{km}$, respectively [1]. Also, in the United States, Environmental Protection Agency demands that emission rates of $\mathrm{NO}_{\mathrm{x}}, \mathrm{PM}$ and unburned hydrocarbons (UHCs) for heavy-duty diesel engines should not exceed $0.27 \mathrm{~g} / \mathrm{kWh}, 0.013 \mathrm{~g} / \mathrm{kWh}$ and 0.19 $\mathrm{g} / \mathrm{kWh}$, respectively [2]. Therefore, there is an ongoing re- search on diesel engines to meet those strict emission regulations [3]. Advanced combustion methods [4,5], alternative fuels [6-8] and exhaust gas recirculation (EGR) [9] have been highly successful to decrease emission rates on diesel engines. Engine manufacturers also outfit current vehicles with EAT systems which are effective to reduce tailpipe emission rates. Aforementioned on-engine techniques are generally combined with EAT systems in order to curb emission rates satisfactorily on automotive vehicles.

Conventional EAT systems utilized on highway vehicles include Selective Catalytic Reduction (SCR), Diesel Particulate Filter (DPF) and Diesel Oxidation Catalyst (DOC). While SCR is used to decrease $\mathrm{NO}_{\mathrm{x}}$, DPF is utilized to reduce PM and DOC is implemented to diminish UHCs and carbon monoxide (CO) emissions on highway vehicles. 


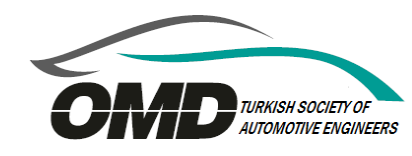

Those systems are highly practical to cut down emission rates. However, they also have a significant shortcoming: their effectiveness highly depends on temperature. EAT systems generally need to be above $250^{\circ} \mathrm{C}$ for effective performance [10-15]. At medium to high loads, this does not pose a problem since exhaust temperatures mostly exceed $250^{\circ} \mathrm{C}$. However, at cold-starts and low load operations, exhaust temperatures remain much below $250^{\circ} \mathrm{C}$ and thus, EAT systems cannot be warmed up above $250^{\circ} \mathrm{C}$ [16]. On highway vehicles, there is a need to sustain fast EAT warm-up - which requires high exhaust temperature and high exhaust flow rate - in order to obtain high emission conversion efficiency and thus, reduce emission rates.

Modulating intake valve closure (IVC) is one way to rise exhaust temperatures [17,18]. Retarding or advancing nominal IVC timing decreases air intake and increases engineout temperatures. Another air-reducing technique is to use cylinder deactivation (CDA) [19-22]. In this method, some of the cylinders on the system are inactivated through switching off both valves and fuel injection. More fuel is used on active cylinders to keep load constant which reduces air-to-fuel ratio (AFR) in those cylinders and thus, exhaust temperature is elevated. Mayer et al. achieves high exhaust temperatures via applying intake throttling on a diesel engine system as well [23]. Control of turbocharger waste-gate opening also decreases air induction and boosts exhaust temperatures [24,25]. Although those aforementioned methods are noticeably effective at elevating engineout temperatures, they also result in a dramatic reduction on exhaust flow rate which affects EAT warm-up negatively.

Researchers study fuel-consuming thermal management methods as well [26]. One of them is to utilize early exhaust valve opening (EEVO) [27]. EEVO causes fuel inefficiency in the system due to reduced expansion work. However, extra fuel injection and early release of hot in-cylinder gas can maintain exhaust temperatures above $250^{\circ} \mathrm{C}$ at low loads [28]. Fuel injection timing modulation and post-fuel injection can also be applied for improved exhaust thermal management with a moderate deterioration on fuel consumption [29,30]. Another fuel-inefficient engine-base technique is to use internal exhaust gas recirculation (IEGR) [31]. Some previous studies investigate engine-independent methods such as electrical heating, utilization of reformers and heat storage materials to enhance EAT warm-up as well [32-34]. Those previous techniques worsen fuel consumption, however, they maintain both high exhaust temperatures and high exhaust mass flow rates at low loads which are significant for EAT warm-up. The potential of enginedependent EAT heat-up methods are not thoroughly examined yet. Therefore, there is an ongoing research for improved EAT warm-up through different engine-base thermal management techniques [35].

The aim of this work is to demonstrate that EVO modulation is a highly effective method for EAT warm-up at low-loaded operations of diesel vehicles. In this study, un- like previous studies, late exhaust valve opening (LEVO) is shown to be as effective as EEVO at improving exhaust temperatures. Also, effect of EEVO \& LEVO on exhaust mass flow rate - which is as critical as exhaust temperature on EAT heat up - is considered. Both techniques can rise turbine-out exhaust temperature above $250^{\circ} \mathrm{C}$ and have higher exhaust mass flow rates compared to nominal case. Although the method results in high fuel consumption penalty (up to $20 \%$ ), it accelerates EAT warm-up process through improving heat transfer rates up to $140 \%$. Considering the fuel penalty is valid only during EAT warm-up and the method does not require any extra component (such as an after-burner or an electrical heater) to be placed on the system, it can be viewed as a practical technique to decrease the time for EAT warm-up. Therefore, emission rates during warm-up can be noticeably improved through modifying engine valve design parameters.

\section{Methodology}

\subsection{Engine Properties and Simulation Model}

Diesel engine properties utilized in this numerical work are listed on Table 1 below. It is a high-duty four-stroke sixcylinder diesel engine which uses a turbocharger for airinduction. Highway trucks and urban buses generally utilize those kinds of diesel engines which need EAT thermal management during cold-starts and low-loaded operations.

The simulation model of the diesel engine is seen on Figure 1 below. Lotus Engine Simulation (LES) - a onedimensional program for engine modeling - is used to form the model $[36,37]$ with the specifications given on Table 1 . A compressor, an intercooler and intake pipe elements which connect those two to the intake ports and intake valves constitute the intake section of the engine system.

Table 1. Engine specifications.

\begin{tabular}{c|c}
\hline Model & Four-stroke diesel engine \\
\hline Number of cylinders & 6 \\
\hline Stroke $(\mathrm{mm})$ & 124 \\
\hline Bore $(\mathrm{mm})$ & 107 \\
\hline Connecting rod length $(\mathrm{mm})$ & 192 \\
\hline Compression ratio & 17.3 \\
\hline Air-intake & Turbocharged \\
\hline Cylinder firing order & $1-5-3-6-2-4$ \\
\hline Nominal EVO & $20^{\circ} \mathrm{CA} \mathrm{BBDC}$ \\
\hline Nominal EVC & $20^{\circ} \mathrm{CA} \mathrm{ATDC}$ \\
\hline Nominal IVO & $20^{\circ} \mathrm{CA} \mathrm{BTDC}$ \\
\hline Nominal IVC & $25^{\circ} \mathrm{CA} \mathrm{ABDC}$ \\
\hline Exhaust valve max. lift $(\mathrm{mm})$ & 10.0 \\
\hline Intake valve max. lift $(\mathrm{mm})$ & 8.5 \\
\hline EVO modulation & Between $75^{\circ} \mathrm{CA}$ ABDC and \\
\hline
\end{tabular}




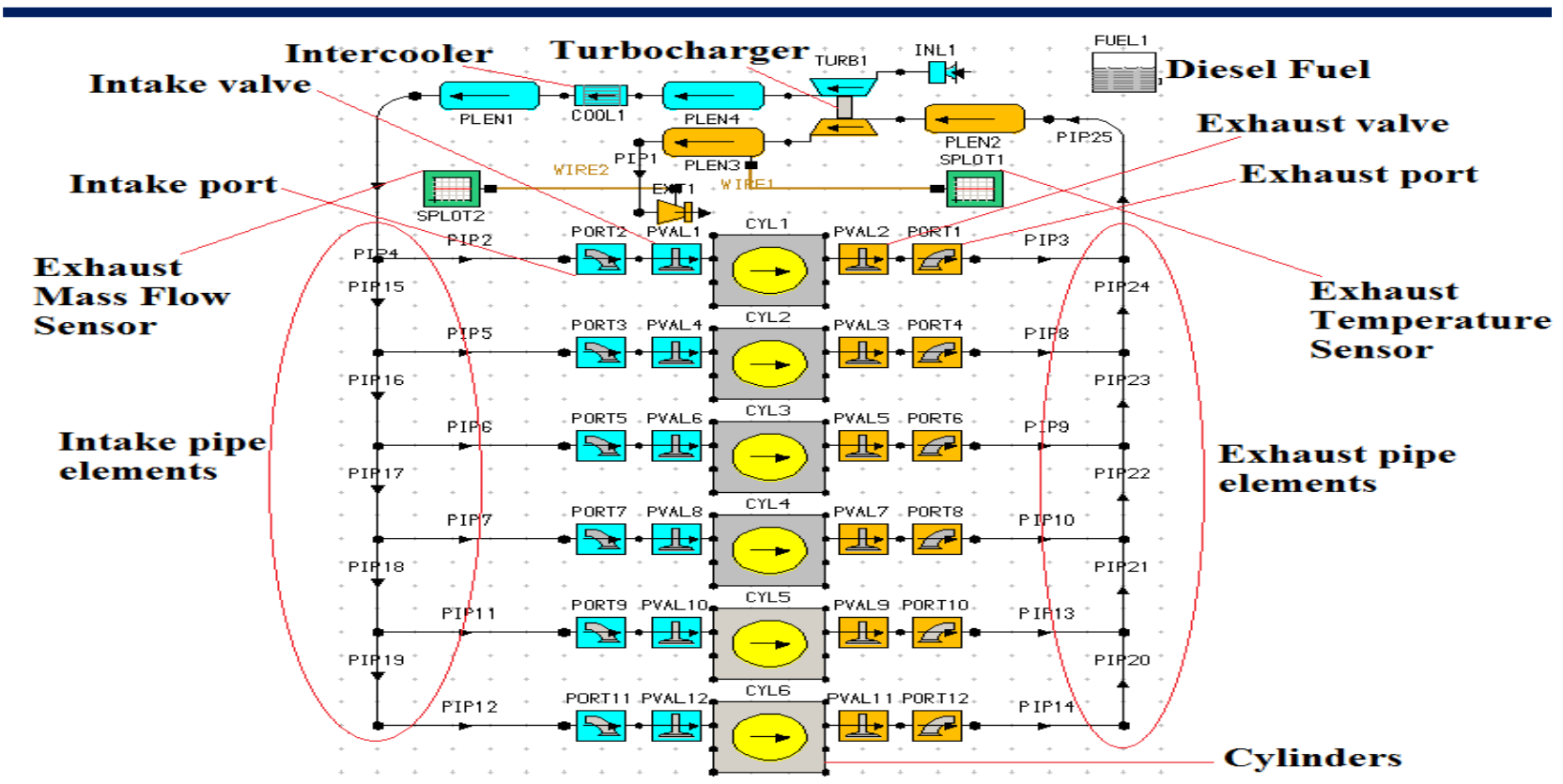

Fig. 1. Engine model.

Inducted air inside the cylinders is compressed, diesel fuel (seen as FUEL 1) is injected to the compressed air and combustion occurs at the end of compression phase. After combustion, on exhaust phase, exhaust valves open close to bottom dead center of the cylinder and exhaust gas starts to flow through exhaust ports and exhaust pipe elements. Finally it expands within the turbine and leaves the system.

The model is used on a previous study by the author to demonstrate that exhaust temperatures can be increased above $250^{\circ} \mathrm{C}$ at low loads through reasonable control of IVC [17]. Nominal valve timings and valve lifts on Table 1 are also taken from Ref.[17]. On this earlier work, the model is also validated with the experimental results of a similar diesel engine [38]. IVC modulation is found to be highly successful to rise engine-out temperatures, however, it causes a dramatic reduction on exhaust flow rate which decreases exhaust gas energy and thus, affects EAT warmup negatively. Unlike Ref.[17], this study intends to increase exhaust gas energy. Therefore, it implements a different valve timing actuation - EVO modulation - on the same model to improve EAT warm-up which requires both high exhaust temperatures and high exhaust flow rates.

An EAT system is not built on the engine model shown on Figure 1. Exhaust gas leaving the turbine at PLEN3 is assumed to flow directly towards a virtual three-way catalytic convertor (TWC) system - a common EAT system on highway vehicles - which includes DOC, DPF and SCR, respectively. Therefore, exhaust temperature and exhaust flow rate instantly affect the temperature of those components on a TWC system. SPLOT1, illustrated as exhaust temperature sensor, measures the turbine exit temperature (TET) which is one of the key elements on EAT warm-up. TET should be kept above $250^{\circ} \mathrm{C}$ for effective EAT per- formance. However, another key element on EAT heat-up exhaust mass flow rate - should also be considered. It is determined via SPLOT2 - exhaust flow rate sensor - on Figure 1. High TETs and high exhaust flow rates are needed to accelerate the EAT warm-up. Therefore, nominal EVO timing seen on Table 1 is altered backward and forward in order to elevate exhaust temperatures above $250^{\circ} \mathrm{C}$ with high exhaust flow rates.

\subsection{Mathematical Equations}

Engine brake power on the model is found with the equation below [39]:

$$
P_{B}=\left(B M E P * N * Z * V_{d} / 60 n_{r}\right)
$$

where $\mathrm{V}_{\mathrm{d}}$ represents displaced volume per cylinder, $\mathrm{N}$ shows speed (RPM) of the diesel engine, $\mathrm{Z}$ is the total cylinder number and $\mathrm{n}_{\mathrm{r}}$ is the number of revolutions per cycle and taken as 2 since the study examines a four-stroke engine. BMEP is maintained constant during EVO modulation through fuel injection rate adjustment. Thus, $P_{B}(\mathrm{~kW})$, total useful work produced, is kept constant in the system as well.

Volumetric efficiency - effectiveness of the engine breathing - is calculated with the formulation below [39]:

(2)

$$
\eta_{v o l}=\left(2 * 10^{3} \dot{m}_{a} / 30 N V_{d} \rho_{a}\right)
$$

where air density at inlet is represented with $\rho_{\mathrm{a}}$ and air mass flow rate into the cylinders is shown with $\dot{m}_{a}$.

One dimensional model of pipe gas dynamics is applied in the program for the fluid flow inside intake \& exhaust 
pipe elements. 2-step Lax-Wendroff technique is utilized to solve energy, mass and momentum equations [40].

The program allows the user to model combustion with two-part Wiebe equation. This model mainly includes two phases: The first phase is the premixed phase and the latter is the diffusion phase. The equations below are utilized in the program to calculate the mass fraction of the burned fuel in premixed and diffusion combustion phases, respectively [41]:

$$
\begin{aligned}
& m_{\text {premix }}=1-\left[1-\left[\theta / \theta_{b}\right]^{C_{1}}\right]^{C_{2}} \\
& m_{\text {diff }}=1-e^{-A\left(\theta / \theta_{b}\right)^{M+1}}
\end{aligned}
$$

where Wiebe coefficients $-\mathrm{C}_{1}$ and $\mathrm{C}_{2}$ in premixed phase, $\mathrm{A}$ and $\mathrm{M}$ in diffusion phase - are determined appropriately for the validation with the experimental results. $\theta_{\mathrm{b}}$ denotes the total burn angle and $\theta$ represents the burn angle of the combustion period.

Friction loss is predicted through using Sandoval \& Heywood friction model [42]. It is a comprehensive model and friction loss thanks to auxiliaries, engine valves, reciprocating and rotating parts of the engine are first examined separately and then the sum of those items gives the total friction loss - total friction mean effective pressure (FMEP) - in the system with the formula below:

$$
\begin{aligned}
& F M E P_{\text {total }}=F M E P_{\text {rotating }}+F M E P_{\text {reciprocating }}+ \\
& \text { FMEP } P_{\text {auxiliary }} \\
& F M E P_{\text {valvetrain }}+
\end{aligned}
$$

Annand heat transfer model is preferred to calculate the heat loss from cylinders to the environment. Annand heat transfer model is given with the equation below [43]:

$$
A R e^{B}=h B_{c y l} / k
$$

where $\mathrm{k}$ shows the thermal conductivity of gas in the cylinder, $\mathrm{h}$ represents the heat transfer coefficient, B is the cylinder bore, Re is the Reynolds number. A and B denote the Annand coefficients for open \& closed cycles of the engine. Heat transfer per unit area is found with equation (7) [43]:

$$
d Q /_{A}=h\left(T_{G}-T_{W}\right)+C\left(T_{G}^{4}-T_{W}^{4}\right)
$$

where $T_{G}$ and $T_{W}$ define the temperatures of in-cylinder gas and cylinder wall. $\mathrm{C}$ in equation (7) is also an Annand coefficient - similar to A and B in equation (6) - which is considered only during closed cycle.

Brake specific fuel consumption (BSFC) of the model is calculated with the formulation below [39]:

$$
B S F C=\dot{m}_{f} / P_{B}
$$

where $\dot{m}_{f}(\mathrm{~g} / \mathrm{h})$ represents diesel fuel mass flow rate.

Brake thermal efficiency (BTE) of the model is determined with equation (9) below [39]:

$$
\eta_{B T E}=3600\left[P_{B} / \dot{m}_{f} Q_{L H V}\right]
$$

where $\mathrm{Q}_{\mathrm{LHV}}$ denotes diesel fuel heating value which is taken as $42600 \mathrm{~kJ} / \mathrm{kg}$ on the model.

\subsection{EVO Modulation}

The implementation of EVO modulation on engine valve system is demonstrated on Figure 2 below. As seen, intake valve opening \& closing timings are kept fixed. Only EVO timing is altered. It is either advanced from the nominal timing and opened closer to top dead center (TDC) - shown as EEVO - or retarded from the base timing and opened after bottom dead center (BDC) - shown as LEVO - on the system. Maximum exhaust valve lift is held constant as $10.0 \mathrm{~mm}$ during EVO modulation.

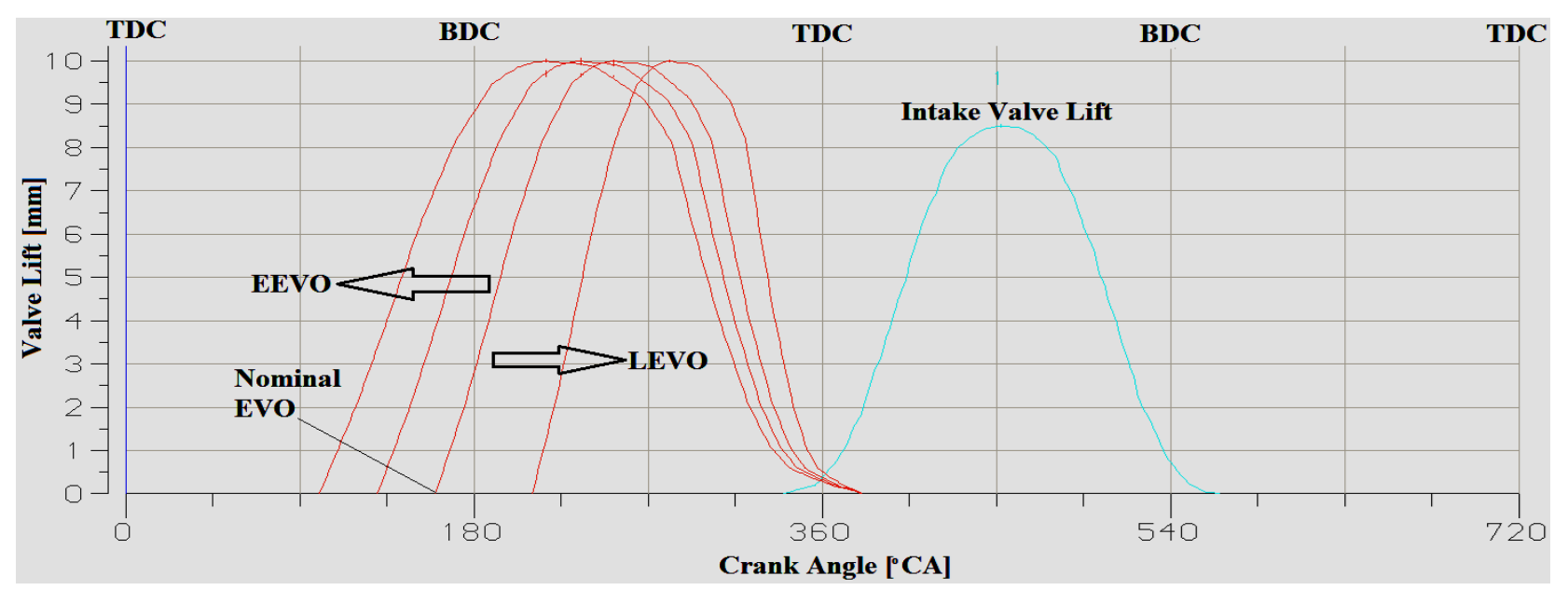




\section{Results and Discussion}

Fig. 2. Change of exhaust valve lift with EVO modulation

Engine model illustrated on Figure 1 is set to operate at 1200 RPM engine speed and 2.5 bar BMEP engine load. Nominal exhaust temperature at this low loading operation generally remains below $250^{\circ} \mathrm{C}$ which is insufficient for effective EAT performance. EVO modulation is presented as a thermal management method for improved EAT warmup. As EVO is altered, fuel injection rate on the system is adjusted to keep BMEP constant at 2.5 bar.

Change of turbine-out exhaust temperature during EVO modulation is shown on Figure 3 below. Exhaust temperature at nominal EVO timing falls below $200^{\circ} \mathrm{C}$ which is highly low for effective EAT management. Thus, emission conversion efficiency is low at nominal operation. However, as EVO is either advanced or retarded sufficiently from the nominal, exhaust temperature exceeds $250^{\circ} \mathrm{C}$ and emission conversion efficiency is improved.

In EEVO mode, exhaust valve timing begins to open relatively far from the BDC and closer to TDC. As the opening timing approaches TDC - where combustion occurs -, hotter in-cylinder gas starts to leave the cylinder since the expansion period is shortened in EEVO mode. The gas has lower time - lower closed cycle - to expand before discharge starts and thus, it is required to flow to exhaust ports with higher temperatures. While the improvement on exhaust temperature is relatively low until EVO gets $70^{\circ} \mathrm{CA}$ before $\mathrm{BDC}$, it starts to accelerate above that timing and reaches its peak at $105^{\circ} \mathrm{CA}$ before BDC. Those high TETs in EEVO mode are achieved through fuel consumption penalty as shown on Figure 4. As the fuel injection rises at advanced EVO timings, there is a also a steady reduction on AFR as seen on Figure 5.

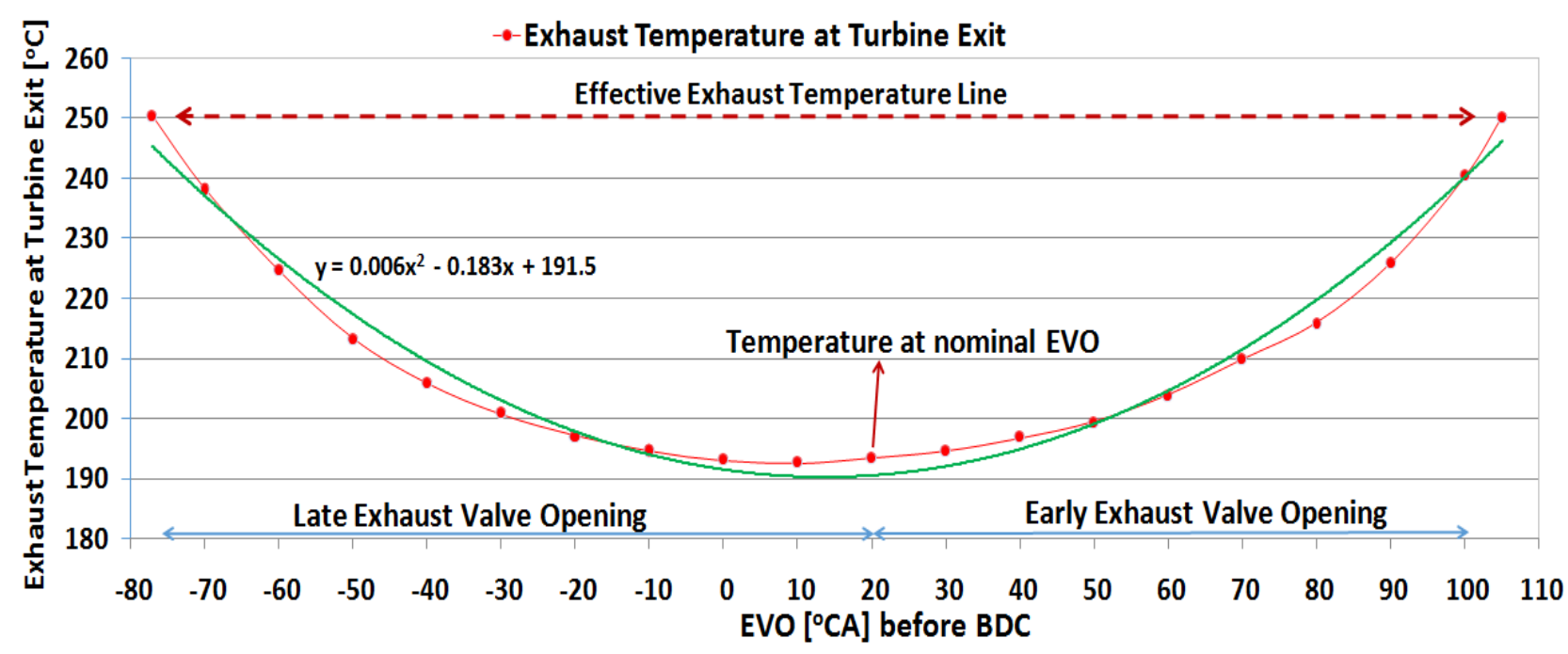

Fig. 3. Effect of EVO modulation on exhaust temperature.

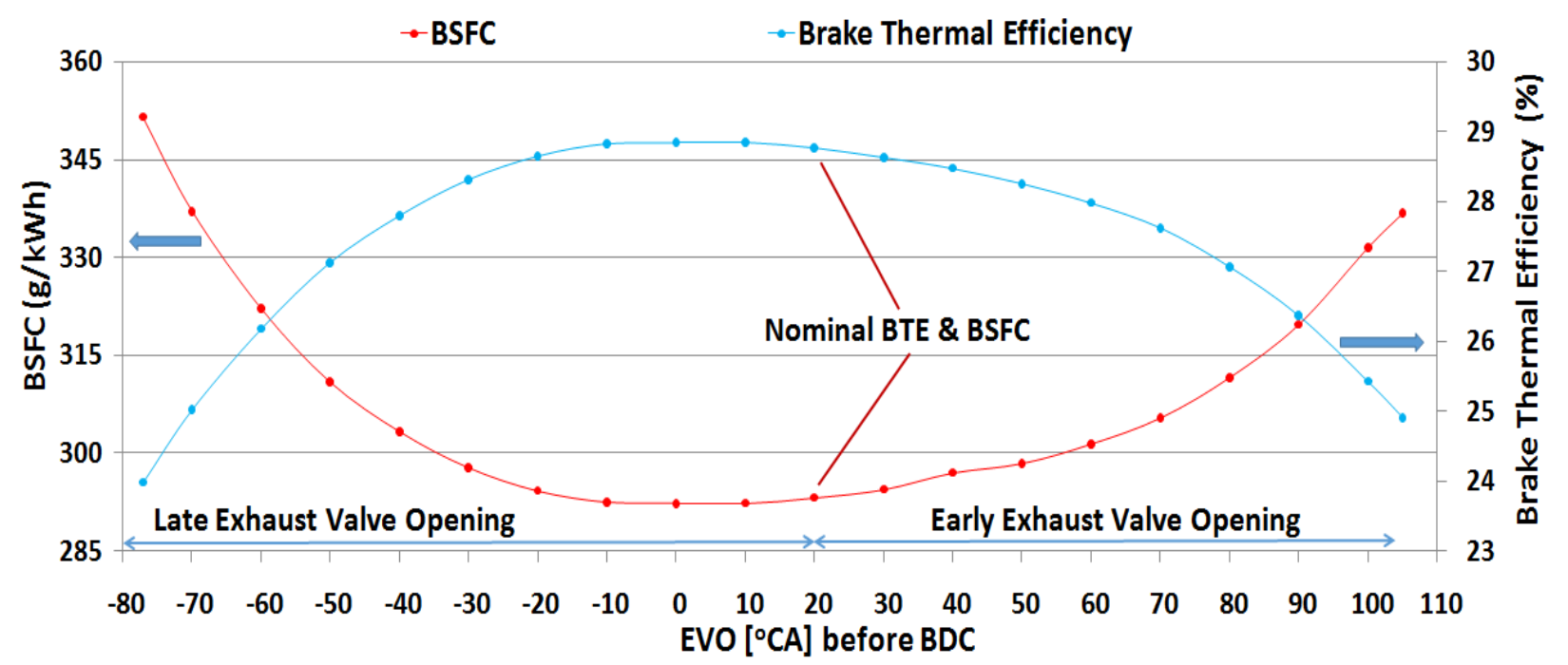

Fig. 4. Effect of EVO modulation on BSFC and BTE. 


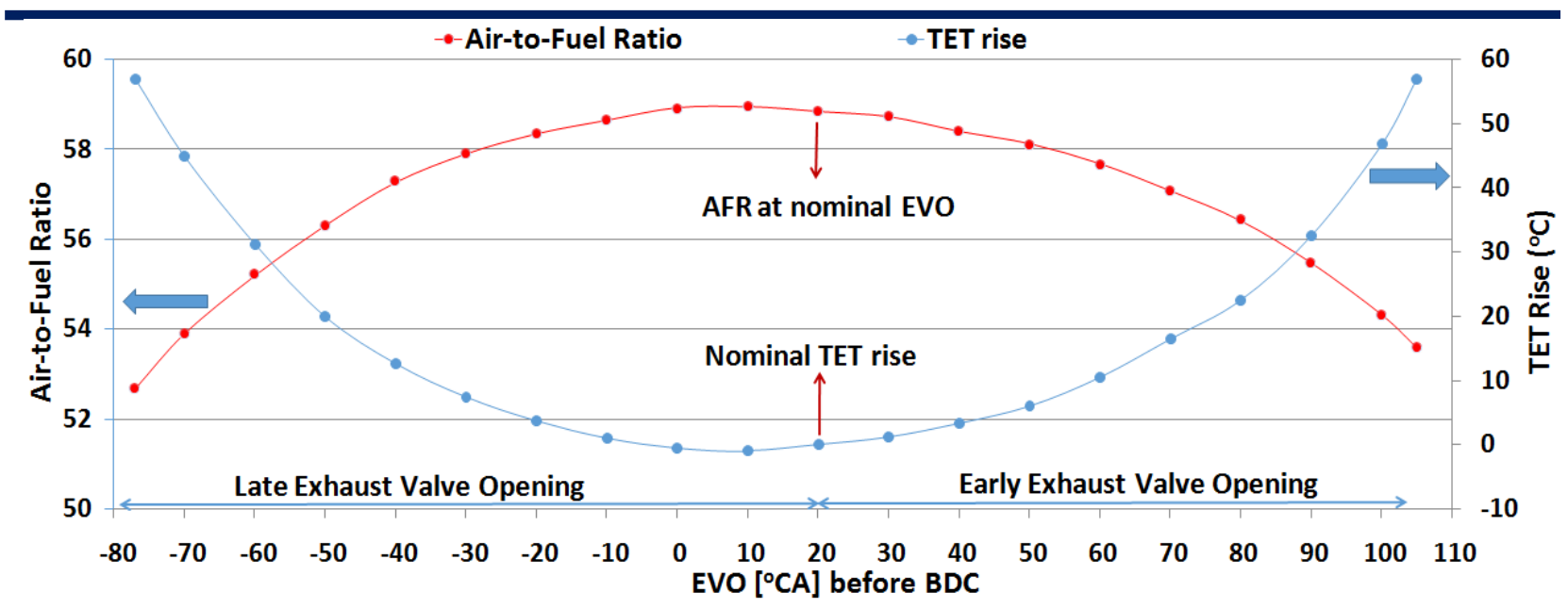

Fig. 5. Effect of EVO modulation on AFR and TET rise.

In LEVO mode on Figure 3, EVO timing firstly gets closer to BDC and then it starts to move away from the BDC. It is retarded in exhaust stroke of the cycle until TET remains above $250^{\circ} \mathrm{C}$. At low-retarded EVO timings (until it gets $-20^{\circ} \mathrm{CA}$ before $\mathrm{BDC}$ ), there is not a radical change on exhaust temperatures. This is due to the insignificant change on BSFC and AFR as illustrated on Figures $4 \& 5$ at those timings. However, as EVO is retarded above $-20^{\circ} \mathrm{CA}$, BSFC rises, AFR decreases - similar to EEVO mode - and thus, a considerable TET rise is achieved in the system. It can be derived that TET improvement is inversely proportional with AFR in the system. In fact, this can be predicted in the system since utilizing more fuel in both modes leads to richer mixture (compared to nominal condition) in the cylinder and thus, the system produces the same power with lower efficiency - reduced BTE on Figure 4 - but with much higher TETs.

The effect of BSFC rise on cylinder heat loss and maximum in-cylinder pressure $\left(\mathrm{P}_{\max }\right)$ is shown on Figure 6. Using higher fuel leads to higher $\mathrm{P}_{\max }$ at both EEVO \& LEVO timings. Those elevated $P_{\max }$ values cause higher in-cylinder temperatures and thus, heat loss from the cylinders increases in the system. The latest EVO timing requires more
BSFC (close to $5 \%$ ) compared to the earliest EVO timing on Figure 4. This is the reason why cylinders suffer the highest heat loss and $\mathrm{P}_{\max }$ reaches its peak in LEVO mode during EVO modulation on Figure 6. It can also be derived from Figures $4 \& 6$ that $P_{\max }$ is inversely proportional with the BTE during EVO modulation. The lower the BTE is, the higher the $\mathrm{P}_{\max }$ should be increased in order to maintain constant engine load.

Open and closed cycle efficiency of the system can be examined to understand why fuel inefficiency occurs during EVO modulation. Open-cycle efficiency (OCE) - where either intake or exhaust valves are open - determines how effective the in-cylinder gas exchange is in the system. OCE is calculated with [44]:

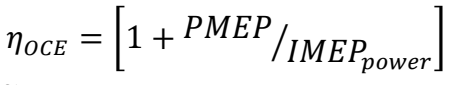

where IMEP power \& PMEP denote the indicated mean effective pressure during power stroke of the engine cycle and engine pumping loss, respectively.

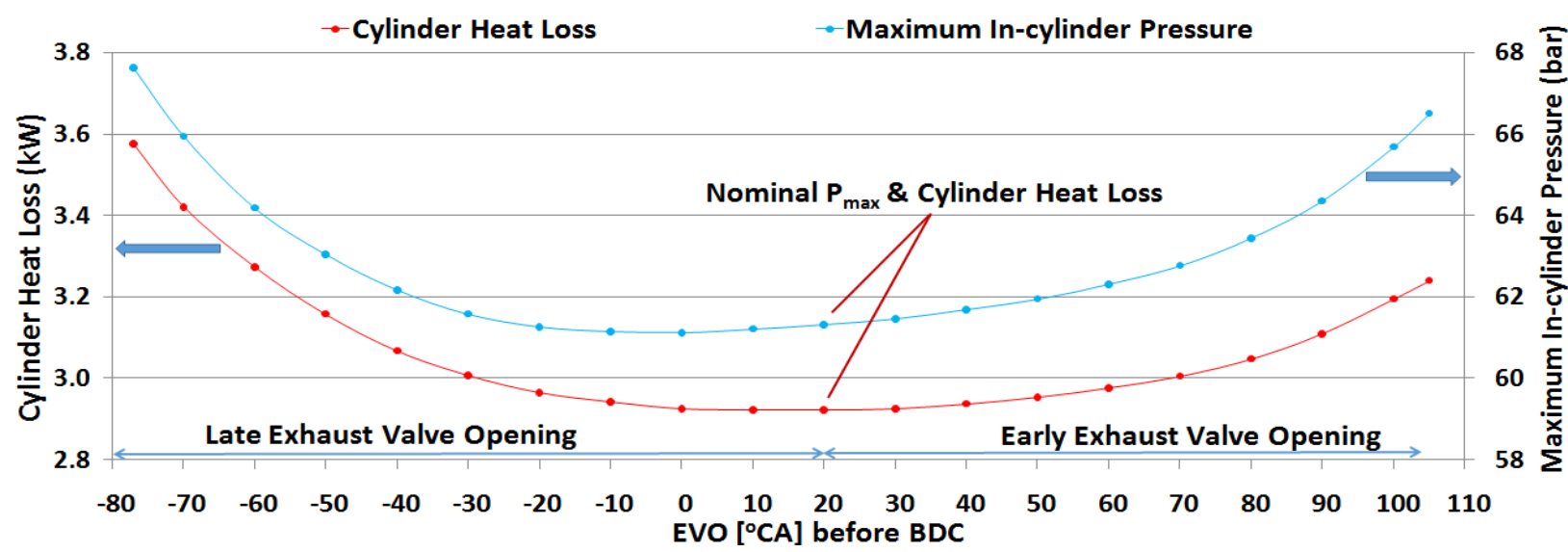


Fig. 6. Effect of EVO modulation on cylinder heat loss and $\mathrm{P}_{\max }$.

Efficiency of the cycle where neither intake nor exhaust valves are open - closed cycle efficiency (CCE) - evaluates how effective diesel fuel energy is converted into piston work. CCE is found with the following equation [44]:

$$
\eta_{C C E}=\left[I M E P_{\text {power }} /\left(\dot{m}_{f} Q_{L H V} / N * V_{d}\right)\right]
$$

Change in OCE and CCE at EEVO \& LEVO modes is shown on Figure 7. OCE decreases on Figure 7 when EVO is moved either side of the nominal timing. This is due to the rise on pumping loss in both retarded \& advanced EVO timings as illustrated on Figure 8. It is seen on Figure 7 that OCE reduces more in LEVO mode compared to EEVO

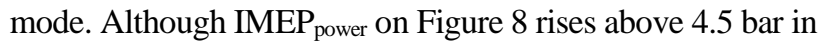
LEVO mode - which can be predicted considering the $20 \%$ rise on BSFC on Figure 4 -, pumping loss increases more than twice (from -0.6 bar to -1.4 bar) due to shorter exhaust opening duration and difficulty in discharging exhaust out of the cylinder. The reduced BTE in LEVO mode on Figure 4 (from $29 \%$ to $24 \%$ ) seems to stem from the highly deterio- rated OCE on Figure 7.

In EEVO mode, unlike LEVO, there is a dramatic reduction on CCE as shown on Figure 7. CCE mainly considers $\mathrm{IMEP}_{\text {power }}$ and fuel injection rate. As seen previously on Figure 4, BSFC rises up to $15 \%$ and $20 \%$ in EEVO \& LEVO modes, respectively. While $\mathrm{IMEP}_{\text {power }}$ in LEVO mode exceeds 4.5 bar, it can barely rise up to 3.9 bar in EEVO mode on Figure 8. Considering the high fuel penalty engine suffers in EEVO mode, the increase in $\mathrm{IMEP}_{\text {power }}$ is quite low. This is due to the early blow-down of the cylinder pressure and lost expansion work in EEVO mode which do not occur during LEVO modulation. Therefore, there is not a significant change in CCE in LEVO mode on Figure 7.

The loss in engine work in EEVO \& LEVO modes can also be illustrated on Figure 9 by examining the change in brake power $\left(\mathrm{P}_{\mathrm{B}}\right)$ at "constant fuel injection rate". The extra energy need of the system for constant engine load can be explicitly inferred from this figure. The system produces up to $5 \mathrm{~kW}$ lower useful power during EVO modulation when injected fuel rate is kept fixed in the system.

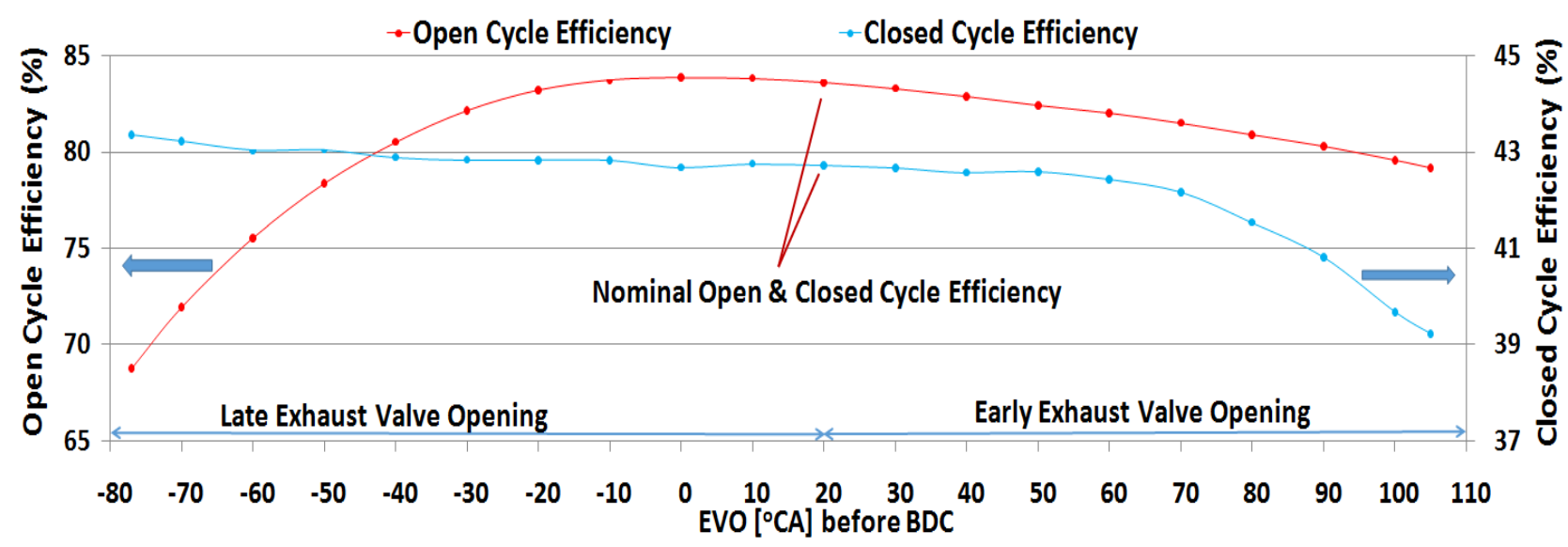

Fig. 7. Effect of EVO modulation on OCE and CCE.

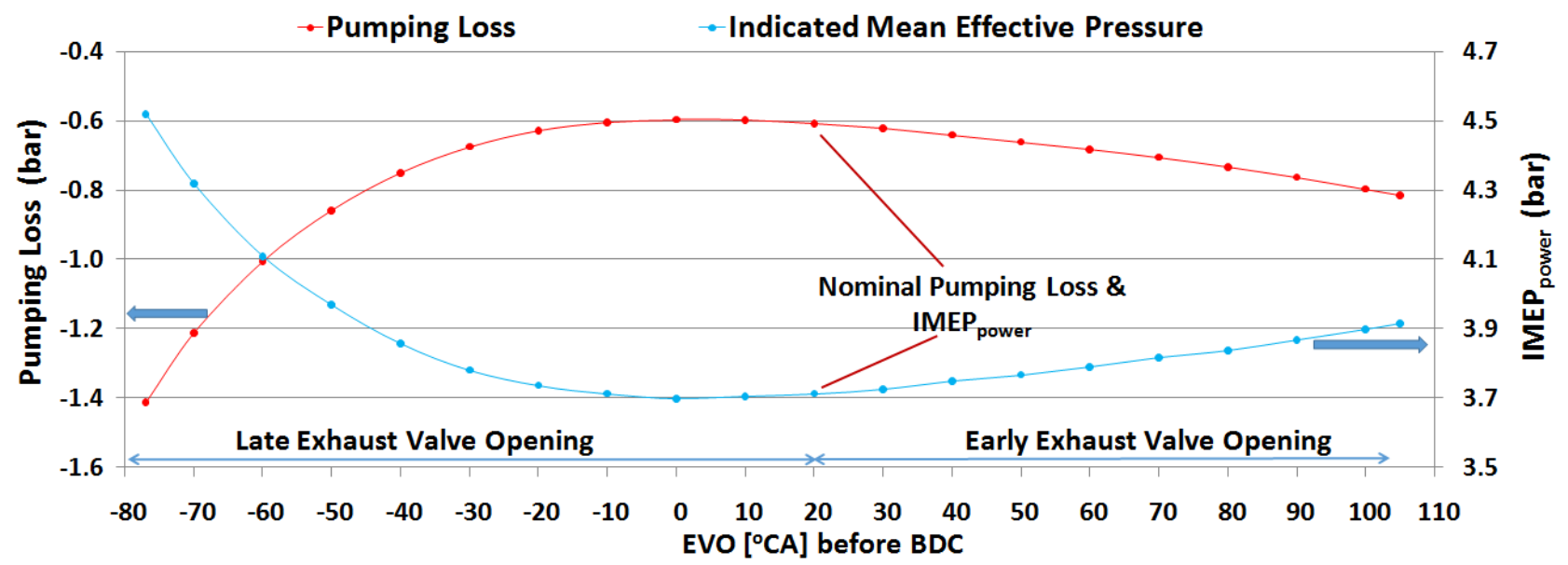

Fig. 8. Effect of EVO modulation on pumping loss and indicated mean effective pressure. 


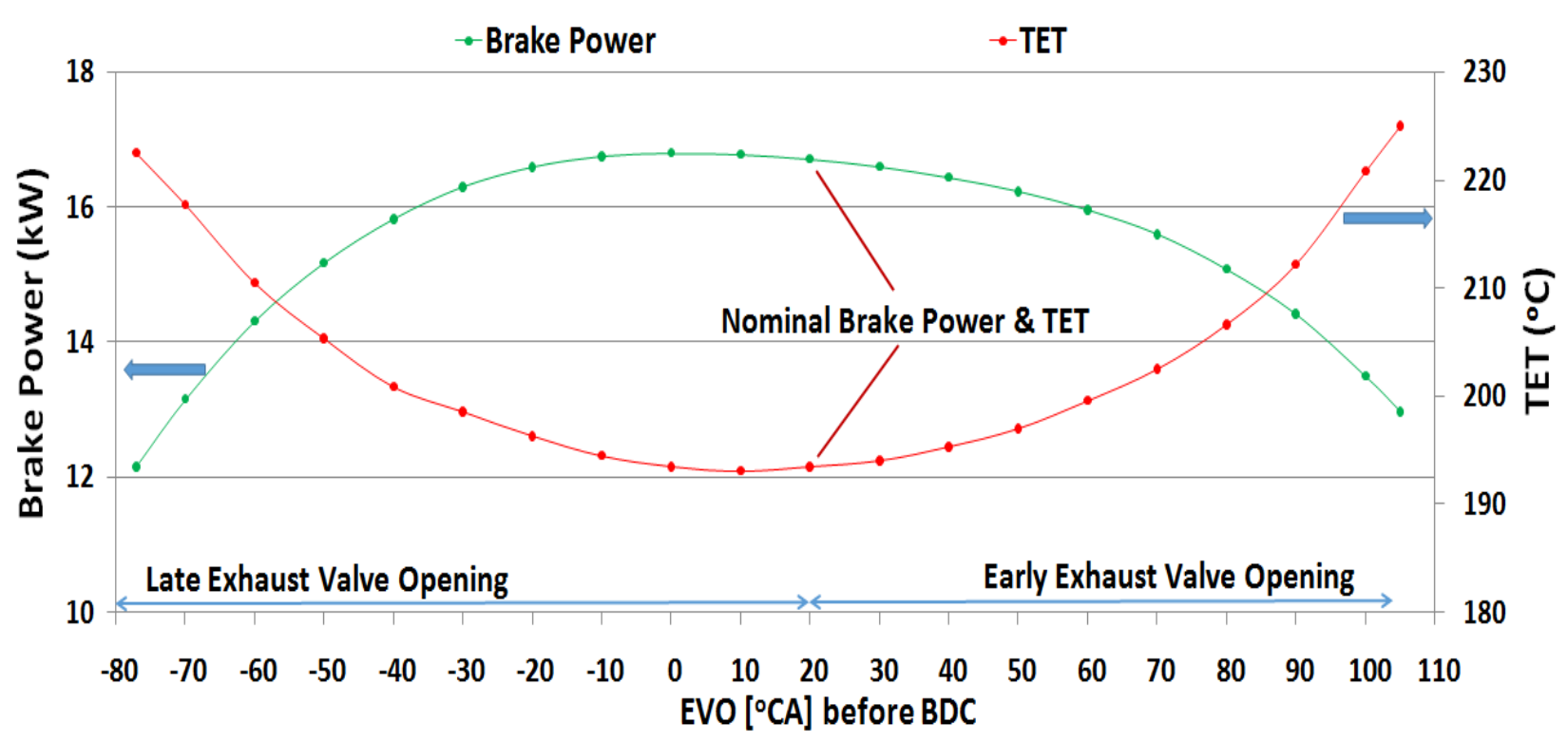

Fig. 9. Change in $\mathrm{P}_{\mathrm{B}}$ and TET at constant fuel injection rate.

It is seen on Figure 9 that the system is required to operate with lower power as EVO is modulated either left or right from the nominal timing. There is a higher reduction on brake power in LEVO mode and thus, extra fuel need is much higher for constant load management as seen previously on Figure 4. Even if no additional fuel is injected into the cylinders, TET still rises in the system. Due to inefficient operation, higher fraction of fuel energy is converted to exhaust energy and thus, exhaust temperature rises in the system. However, not only is engine-out temperature still below $250^{\circ} \mathrm{C}$, but also the system is faced with engine load variation which is not desired during steady-state operations.

As mentioned previously on introduction section, EAT warm-up not only depends on TET, but also exhaust mass flow rate. Therefore, change in exhaust mass flow rate $\left(\dot{m}_{\text {exh }}\right)$ \& exhaust gas energy (EGE) during EVO modulation is examined on Figure 10.

In EEVO mode, there is a steady rise on both $\dot{m}_{\text {exh }}$ and EGE. Considering the $\dot{m}_{\text {exh }}$ is the sum of intake air flow rate and fuel injection rate, it is expected to rise since there is up to $15 \%$ rise on BSFC (Figure 4) in EEVO mode. On Figure 10, $\dot{m}_{\text {exh }}$ seems to be directly proportional with EEVO modulation and approaches $5.0 \mathrm{~kg} / \mathrm{min}$ at most advanced EVO timing where TET exceeds $250^{\circ} \mathrm{C}$ (Figure 3) in the system. Similar to $\dot{m}_{\text {exh }}$, there is a constant improvement on EGE. This is also predicted in the system since EGE is mainly affected by $\dot{m}_{e x h}$ and TET which tend to rise as EVO is moved further from the nominal timing. EGE is increased from $950 \mathrm{~kJ} / \mathrm{min}$ to almost $1300 \mathrm{~kJ} / \mathrm{min}$ which is highly positive for EAT warm-up.

In LEVO mode, there is a slight reduction on $\dot{m}_{\text {exh }}$ at low retarded EVO timings due to the insignificant improvement on BSFC and OCE (Figures $4 \& 7$ ). However, as EVO is retarded further, BSFC is increased to compensate the brake power loss (Figures $4 \& 9$ ) and thus, $\dot{m}_{\text {exh }}$ moves upward in the system. At most retarded EVO timing, $\dot{m}_{\text {exh }}$ exceeds $5.1 \mathrm{~kg} / \mathrm{min}$ which is higher than the value achieved at most advanced EVO timing $(5.0 \mathrm{~kg} / \mathrm{min})$. This stems from the fact that the system at the latest EVO timing suffers higher power loss and higher fuel penalty (Figures $4 \& 9$ ) in comparison to the earliest EVO timing. Achieving higher $\dot{m}_{\text {exh }}$ with a similar TET rise - close to $60^{\circ} \mathrm{C}$ (Figure 5) - enables EGE to remain above $1300 \mathrm{~kJ} / \mathrm{min}$ in LEVO mode as seen on Figure 10. EGE does not rise in LEVO mode as rapidly as it does in EEVO mode. For instance, while EGE exceeds $1000 \mathrm{~kJ} / \mathrm{min} \& 1200 \mathrm{~kJ} / \mathrm{min}$ as EVO is advanced $40^{\circ} \mathrm{CA}$ \& $80^{\circ} \mathrm{CA}$ respectively from the nominal timing; it still remains close to $950 \mathrm{~kJ} / \mathrm{min} \& 1150 \mathrm{~kJ} / \mathrm{min}$ as EVO is retarded $40^{\circ} \mathrm{CA} \& 80^{\circ} \mathrm{CA}$ respectively from the base timing. However, when EVO is retarded or advanced sufficiently from the nominal timing until TET gets $250^{\circ} \mathrm{C}$ (Figure 3), EGE is improved slightly more in LEVO mode on Figure 10.

The change in fuel consumption, exhaust energy and fraction of fuel energy converted to exhaust energy at nominal, earliest EVO $\left(105^{\circ} \mathrm{CA}\right.$ before $\left.\mathrm{BDC}\right)$ and latest $\mathrm{EVO}\left(75^{\circ} \mathrm{CA}\right.$ after BDC) cases is demonstrated on Figure 11. Fuel consumption and exhaust energy at all cases are normalized via considering those engine performance parameters at nominal EVO timing as 1.0. Fraction of fuel energy converted to exhaust energy is found through dividing exhaust energy with the total fuel energy at every particular case. It is seen that although earliest EVO causes a $15 \%$ rise on fuel consumption, it improves exhaust energy $35 \%$ through converting more fuel energy to exhaust energy in comparison to nominal case ( $32 \%$ instead of $27 \%$ ). The same is valid in latest EVO case as well. Exhaust energy is increased $40 \%$ - up to twice the percentage of fuel consumption increase (20\%) - via rising the exhaust energy/total fuel energy rate from 0.27 to 0.32 . 


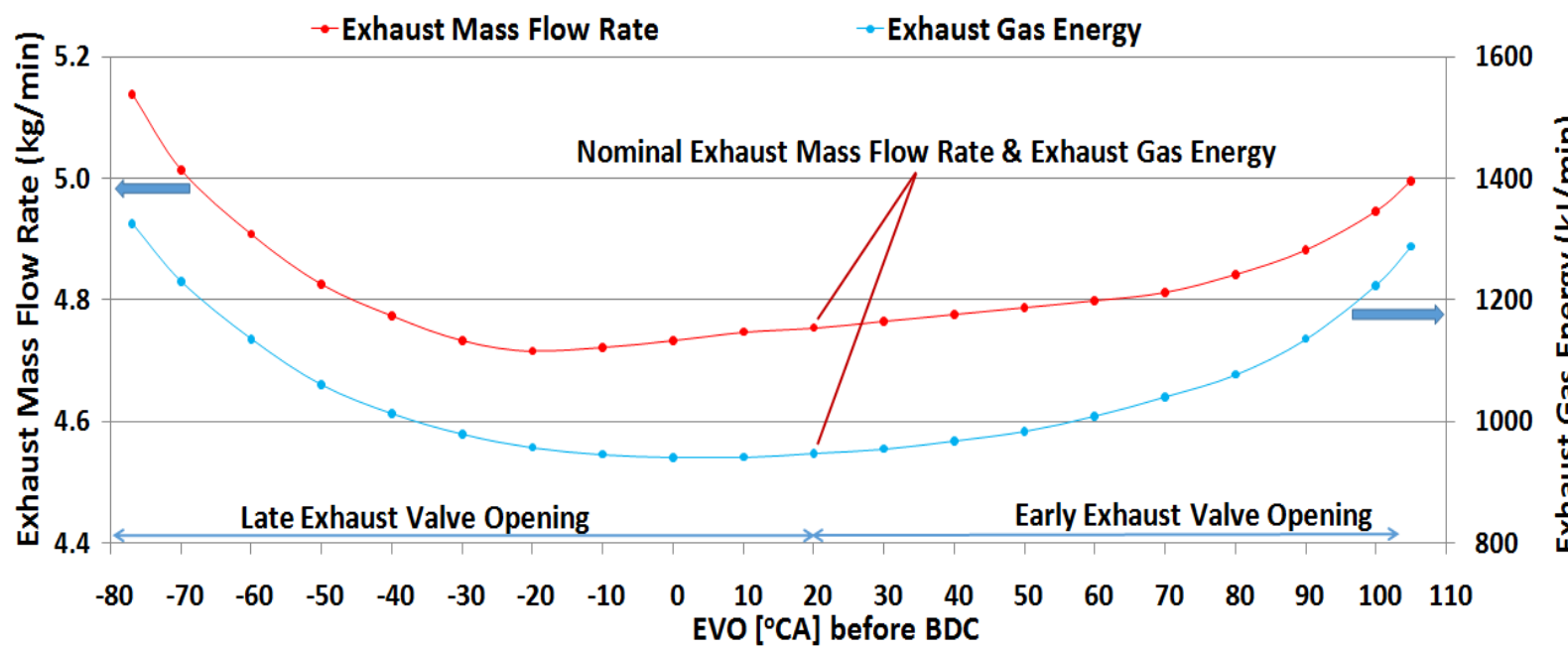

Fig. 10. Effect of EVO modulation on exhaust mass flow rate and exhaust gas energy.

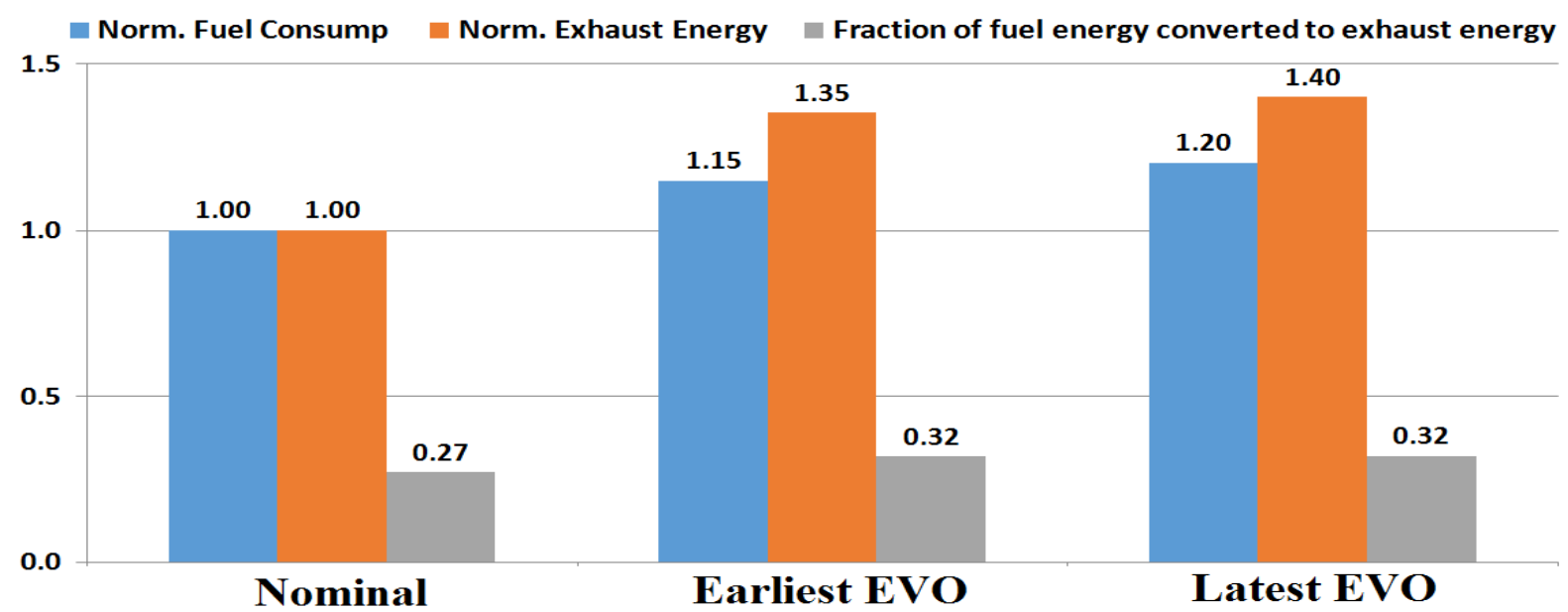

Fig. 11. Comparison of fuel consumption, exhaust energy, fuel energy converted to exhaust energy in nominal, earliest EVO and latest EVO modes.

It is shown previously that EVO modulation is noticeably effective at elevating exhaust temperatures and exhaust flow rates. EAT warm-up relies on both of those parameters. Unless there is an extra component (electrical heater or an afterburner or a thermal storage system) to heat the EAT system, a TWC system on an automotive vehicle can only be heated at low loads and cold starts through heat transfer from the exhaust gas leaving the turbine. Therefore, heat transfer rates during EVO modulation should be examined in order to assess the effectiveness of the technique on EAT warm-up.

Approximate heat transfer rate from exhaust gas to the EAT catalyst bed can be predicted via using the following equation below [45]:

$$
\dot{Q}=C\left[\dot{m}_{\text {exh }}^{4 / 5}\right]\left[T_{\text {exhaust }}-T_{E A T \text { catalyst bed }}\right]
$$

where $\dot{Q}$ shows the heat transfer rate, $\mathrm{T}_{\text {exhaust }}$ represents ex- haust temperature flowing through the EAT system (which is considered as TET in this study), $\mathrm{T}_{\mathrm{EAT} \text { catalyst bed }}$ denotes the temperature of the EAT system, $\dot{m}_{\text {exh }}$ is the exhaust flow rate and finally $\mathrm{C}$ is a constant which is related with the geometry and material of the EAT system.

Formula (12) allows one to evaluate the heat transfer rate to the EAT system at each catalyst bed temperature. In the study, diesel engine system is assumed to operate in a steady state manner at 1200 RPM and 2.5 bar BMEP during EVO modulation. Therefore, $T_{\text {exhaust }}$ and $\dot{m}_{\text {exh }}$ do not change at nominal, earliest EVO and latest EVO cases. Only $\mathrm{T}_{\text {EAT catalyst bed }}$ changes in the system. All heat transfer predictions at nominal, earliest EVO and latest EVO cases are normalized through considering the $\dot{Q}$ in nominal case at zero EAT catalyst bed temperature as 1.0.

Normalized $\dot{Q}$ values for nominal, most advanced EVO and most retarded EVO conditions at 2.5 bar BMEP are illustrated on the following Figure 12. 


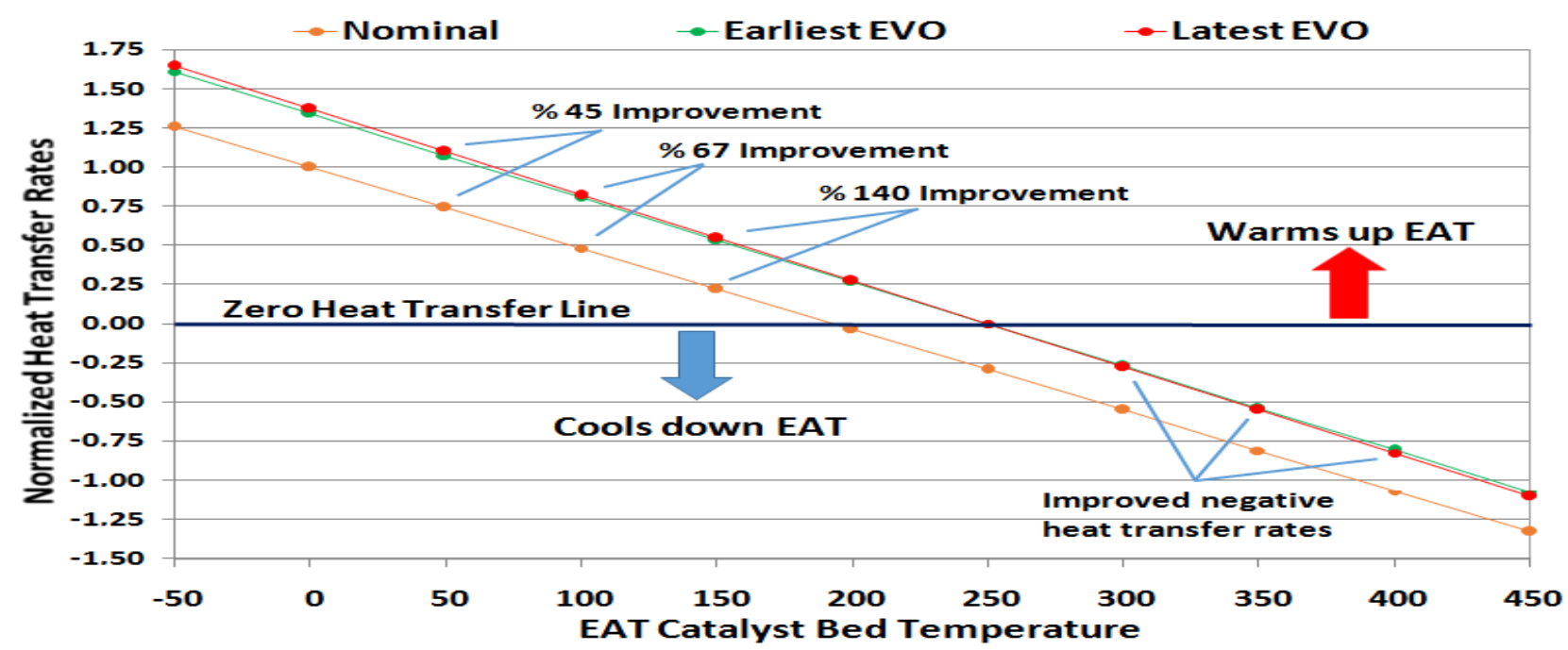

Fig. 12. Change of heat transfer rates with the earliest EVO \& the latest EVO modes at 2.5 bar BMEP.

It is seen on Figure 12 that EAT catalyst bed is warmed up until the zero heat transfer line where exhaust temperature (taken as TET) is equal to catalyst bed temperature $\left(\mathrm{T}_{\text {exhaust }}=\right.$

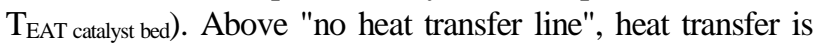
positive and catalyst bed is warmed up as $\mathrm{T}_{\text {exhaust }}$ is greater than $\mathrm{T}_{\text {EAT catalyst bed }}\left(\mathrm{T}_{\text {exhaust }}>\mathrm{T}_{\mathrm{EAT} \text { catalyst bed }}\right)$. However, under "zero heat transfer line", heat transfer is negative and EAT system starts to cool down since $\mathrm{T}_{\text {exhaust }}$ is lower than $\mathrm{T}_{\text {EAT }}$ catalyst bed $\left(\mathrm{T}_{\text {exhaust }}<\mathrm{T}_{\mathrm{EAT} \text { catalyst bed }}\right)$. While the system needs high positive heat transfer rates in order to accelerate the EAT warm-up process, it also requires low negative heat transfer rates in order to maintain EAT system above $250^{\circ} \mathrm{C}$. As shown on Figure 12, positive heat transfer rates in nominal mode are highly low compared to the earliest \& latest EVO modes. Nominal mode can only heat the EAT system until $\mathrm{T}_{\text {EAT catalyst bed }}$ is equal to $195^{\circ} \mathrm{C}$ in a slow manner. This is due to the low $\mathrm{T}_{\text {exhaust }}$ and $\dot{m}_{\text {exh }}$ (Figures $3 \& 10$ ). Although it has low $\dot{m}_{\text {exh }}$ which is beneficial to improve negative heat transfer rates, it still cools EAT catalyst bed faster than the earliest \& latest EVO modes due to low $\mathrm{T}_{\text {exhaust. }}$ It seems that $\mathrm{T}_{\text {exhaust }}$ plays a more important role than $\dot{m}_{\text {exh }}$ when improvement on EAT cool down is considered on Figure 12.

Unlike nominal mode, most advanced \& most retarded EVO modes perform with high $\dot{m}_{\text {exh }}$ and high $\mathrm{T}_{\text {exhaust }}$ which allow for up to $140 \%$ improvement on EAT catalyst bed warm-up. On those modes, EAT system can be warmed up to $250^{\circ} \mathrm{C}$ - effective EAT performance temperature - much faster than nominal mode. Vehicles can spend lower time to achieve high emission conversion efficiency on their TWC systems through EVO modulation and thus, reduce emission rates during cold-starts and low loads. Those two modes have higher $\dot{m}_{\text {exh }}$ due to fuel consumption penalty. However, EAT cool down is still improved at those cases since exhaust temperature rise is high and can overcompensate the positive effect of $\dot{m}_{\text {exh }}$ rise on negative heat transfer rates.

\section{Conclusions}

This numerical study attempts to demonstrate that EVO modulation on automotive diesel vehicles can be a practical way to improve EAT warm-up during cold-starts and lowloaded operations. A previously-validated diesel engine model is set to operate at 1200 RPM engine speed and at 2.5 bar BMEP engine load where TET is not high enough (below $250^{\circ} \mathrm{C}$ ) to manage EAT system in an effective manner.

EVO modulation considers both EEVO and LEVO in the analysis. It is seen that those two methods can rise exhaust temperature more than $55^{\circ} \mathrm{C}$ in the system. While TET in nominal mode remains below $200^{\circ} \mathrm{C}$, it can exceed $250^{\circ} \mathrm{C}$ in EEVO \& LEVO modes.

EEVO \& LEVO techniques require BSFC penalty - up to $15 \%$ and up to $20 \%$, respectively - in the system. While the fuel rise in EEVO mode is due to the $8 \%$ reduction in CCE, the fuel inefficiency in LEVO mode stems from the $17 \%$ reduction in OCE. $\mathrm{P}_{\max }$ is increased to compensate the efficiency loss and thus, engine load is kept constant in the system.

EEVO \& LEVO modes increase $\dot{m}_{e x h}$ due to the rise in fuel injection rate. EGE is improved $35 \%$ at the earliest EVO and $40 \%$ at the latest EVO timings through higher TETs and higher $\dot{m}_{\text {exh }}$. The fraction of fuel converted to EGE is improved from 0.27 to 0.32 at those timings. Effect on EAT warm-up is examined as well. Heat transfer rates to the EAT catalyst bed are enhanced up to $140 \%$ at those timings. Those elevated heat transfer rates can speed up the EAT warm-up process and decrease the time EAT system works inefficiently.

On future works, EVO modulation can be combined with other engine-dependent (late fuel injection, IEGR or CDA) or engine-independent (electrical heating, after-burners or thermal energy storages) exhaust heat up methods to improve the trade-off between EAT warm-up \& fuel consumption penalty. 


\section{Acknowledgment}

I would like to thank Lotus Engineering Company for letting me utilize Lotus Engine Simulation software in this study. This work is supported by Research Fund of the Izmir Katip Celebi University. Project Number: 2019GAP-GIDF-0016.

\section{Nomenclature}

\begin{tabular}{|c|c|}
\hline AFR & : air-to-fuel ratio \\
\hline ATDC & : after top dead center \\
\hline B & : cylinder bore $(\mathrm{mm})$ \\
\hline $\mathrm{BBDC}$ & : before bottom dead center \\
\hline $\mathrm{BDC}$ & : bottom dead center \\
\hline BMEP & : brake mean effective pressure (bar) \\
\hline BSFC & : brake specific fuel consumption $(\mathrm{g} / \mathrm{kWh})$ \\
\hline BTE & : brake thermal efficiency \\
\hline CCE & : closed cycle efficiency \\
\hline CDA & : cylinder deactivation \\
\hline DOC & : diesel oxidation catalyst \\
\hline DPF & : diesel particulate filter \\
\hline EAT & : exhaust after-treatment \\
\hline EEVO & : early exhaust valve opening \\
\hline EGE & : exhaust gas energy \\
\hline EU & : European Union \\
\hline FMEP & : friction mean effective pressure \\
\hline IEGR & : internal exhaust gas recirculation \\
\hline IMEP & : indicated mean effective pressure (bar) \\
\hline IVC & : intake valve closing \\
\hline IVO & : intake valve opening \\
\hline LES & : lotus engine simulation \\
\hline LEVO & : late exhaust valve opening \\
\hline$\dot{m}_{a}$ & : air flow rate $(\mathrm{kg} / \mathrm{min})$ \\
\hline$\dot{m}_{\text {exh }}$ & : exhaust flow rate $(\mathrm{kg} / \mathrm{min})$ \\
\hline$\dot{m}_{f}$ & : fuel flow rate $(\mathrm{g} / \mathrm{h})$ \\
\hline $\mathrm{N}$ & : engine speed (RPM) \\
\hline Norm. & : normalized \\
\hline $\mathrm{NO}_{\mathrm{x}}$ & : nitrogen oxides \\
\hline OCE & : open cycle efficiency \\
\hline $\mathrm{P}_{\mathrm{B}}$ & : brake power $(\mathrm{kW})$ \\
\hline $\mathrm{P}_{\max }$ & : maximum in-cylinder pressure (bar) \\
\hline PM & : particulate matter \\
\hline $\operatorname{Re}$ & : reynolds number \\
\hline RPM & : revolution per minute \\
\hline S & : cylinder stroke $(\mathrm{mm})$ \\
\hline SCR & : selective catalytic reduction \\
\hline TDC & : top dead center \\
\hline TET & : turbine exit temperature \\
\hline TWC & : three-way catalytic convertor \\
\hline $\mathrm{V}_{\mathrm{d}}$ & : displaced volume \\
\hline$\eta_{\mathrm{vol}}$ & : volumetric efficiency \\
\hline$\theta$ & : burn angle (degree) \\
\hline
\end{tabular}

\section{References}

[1] https://www.dieselnet.com/standards/eu/ld.php\#stds. Emission standards, European Union, passenger cars. (Accessed March 2020).

[2] https://nepis.epa.gov/Exe/ZyPDF.cgi?Dockey=P100O9ZZ.pdf. United States Environmental Protection Agency. Heavy-duty highway compression-ignition engine and urban buses: exhaust emission standards, (2010). (Accessed March 2020).

[3] Brijesh, P. and Sreedhara, S. (2013). Exhaust emissions and its control methods in compression ignition engines: a review. International Journal of Automotive Technology, 14(2), 195-206.

[4] Suyin, G., Kiat, H., Mun, K. (2011). Homogeneous charge compression ignition (HCCI) combustion: implementation and effects on pollutants in direct injection diesel engines. Applied Energy, 88(3), 559-567.

[5] Kokjohn S. I., Hanson R. M., Splitter D. A., Reitz R. D. (2011). Fuel reactivity controlled compression ignition (RCCI): a pathway to controlled high efficiency clean combustion. International Journal of Engine Research, 12(3), 209-226.

[6] Caligiuri, C., Renzi, M., Bietresato, M., Baratieri, M. (2019). Experimental investigation on the effects of bioethanol addition in diesel-biodiesel blends on emissions and performances of a micro-cogeneration system. Energy Conversion and Management, 185, 55-65.

[7] Singh, P., Chauhan, S. R., Goel, V. (2018). Assessment of diesel engine combustion, performance and emission characteristics fuelled with dual fuel blends. Renewable Energy, 125, 501-510.

[8] Sezer, İ. (2019). A Review Study on the Using of Diethyl Ether in Diesel Engines: Effects on CO Emissions. International Journal of Automotive Science and Technology, 3(1), 6-20.

[9] Maiboom, A., Tauzia, X., Hetet, J. F. (2008). Experimental study of various effects of exhaust gas recirculation (EGR) on combustion and emissions of an automotive direct injection diesel engine. Energy, 33(1), 22-34.

[10] Hou, X., Ma, Y., Peng, F., Yan, F. and Zhang, X. (2010). Research on temperature characteristics of DPF regeneration technology based on catalytic combustion of fuel injection. In: Proceedings of the Asia-Pacific power and energy engineering conference (APPEEC), Chengdu, China, pp. 1-4. New York: IEEE.

[11] Charlton, S., Dollmeyer, T. and Grana, T. (2010). Meeting the US heavy-duty EPA 2010 standards and providing increased value for the customer SAE International Journal of Commercial Vehicles, 3(1), 101-110.

[12] Allansson, R., Blakeman, P., Cooper, B., Hess, H. (2002). Optimizing the low temperature performance and regeneration efficiency of the continuously regenerating diesel particulate filter (CR-DPF) system. SAE Technical Paper (No. 
2002-01-0428).

[13] Johnson, T. V. (2014). Review of selective catalytic reduction (SCR) and related technologies for mobile applications. In Urea-SCR technology for deNOx after treatment of diesel exhausts, pp. 3-31. Springer, New York, NY.

[14] Ayodhya, A. S. and Narayanappa, K. G. (2018). An overview of after-treatment systems for diesel engines. Environmental Science and Pollution Research, 25(35), 35034-35047.

[15] Praveena, V. and Martin, M. L. J. (2018). A review on various after treatment techniques to reduce NOx emissions in a CI engine. Journal of the Energy Institute, 91(5), 704-720.

[16] Boriboonsomsin K., Durbin T., Scora G., Johnson K., Sandez D., Vu A. (2018). Real-world exhaust temperature profiles of on-road heavy-duty diesel vehicles equipped with selective catalytic reduction. Science of the Total Environment, 634, 909-921.

[17] Basaran, H. U. and Ozsoysal, O. A. (2017). Effects of application of variable valve timing on the exhaust gas temperature improvement. Applied Thermal Engineering, 122, 758767.

[18] Guan, W., Pedrozo, V. B., Zhao, H., Ban, Z. and Lin, T. (2019). Variable valve actuation-based combustion control strategies for efficiency improvement and emissions control in a heavy-duty diesel engine. International Journal of Engine Research, DOI: 10.1177/1468087419846031.

[19] Allen, C. M., Joshi, M. C., Gosala, D. B., Shaver, G. M., Farrell, L. and McCarthy, J. (2019). Experimental assessment of diesel engine cylinder deactivation performance during low-load transient operations. International Journal of Engine Research, DOI: 10.1177/1468087419857597.

[20] Basaran, H. U. (2018). Fuel-saving exhaust after-treatment management on a spark-ignition engine system via cylinder deactivation method. Journal of Thermal Science and Technology, 38(2), 87-98.

[21 Joshi, M., Gosala, D., Allen, C., Srinivasan, S. et al. (2018). Diesel engine cylinder deactivation for improved system performance over transient real-world drive cycles. SAE Technical Paper (No. 2018-01-0880).

[22] Ding, C., Roberts, L., Nielsen, D.C. (2016). Fuel efficient exhaust thermal management for compression ignition engines during idle via cylinder deactivation and flexible valve actuation. International Journal of Engine Research, 17(6), 619-630.

[23] Mayer, A., Lutz, T., Lämmle, C., Wyser, M., Legerer F.(2003). Engine intake throttling for active regeneration of diesel particulate filters. SAE Technical Paper (No. 2003-010381).

[24] Basaran, H. U. (2019). A Simulation Based Study to Improve Active Diesel Particulate Filter Regeneration through Waste-gate Valve Opening Modulation. International Journal of Automotive Science and Technology, 3(2), 32-41.

[25] Bouchez, M. and Dementhon, J. B. (2000). Strategies for the control of particulate trap regeneration. SAE Technical Paper (No. 2000-01-0472).

[26] Honardar, S. et al. (2011). Exhaust temperature management for diesel engines assessment of engine concepts and calibration strategies with regard to fuel penalty. SAE Technical $\mathrm{Pa}$ per (No. 2011-24-0176).

[27] Piano, A., Millo, F., Di Nunno, D. and .Gallone, A. (2017). Numerical analysis on the potential of different variable valve actuation strategies on a light duty diesel engine for improving exhaust system warm-up. SAE Technical Paper (No. 2017-24-0024).

[28] Roberts, L., Magee, M., Shaver, G., Garg, A., McCarthy, J., Koeberlein, E., Holloway, E., Shute, R., Koeberlein, D. and Nielsen, D. (2015). Modeling the impact of early exhaust valve opening on exhaust thermal management and efficiency for compression ignition engines. International Journal of Engine Research, 16(6), 773-794.

[29] Deppenkemper, K., Schoenen, M. and Koetter, M. (2019). Super Ultra-Low NOx Emissions under Extended RDE Conditions - Evaluation of Light-off Strategies of Advanced Diesel Exhaust Aftertreatment Systems. SAE Technical Paper (No. 2019-01-0742).

[30] Ozel, C. T. (2018). Increasing exhaust temperature of an idling light-duty diesel engine through post-injection and intake throttling. SAE Technical Paper (No. 2018-01-0223).

[31] Basaran, H. U. (2019). Improving exhaust temperature management at low-loaded diesel engine operations via internal exhaust gas recirculation. Dokuz Eylul University Faculty of Engineering Journal of Science and Engineering, 21(61), 125-135.

[32] Menne, C., Schrewe, K., Maurer, B. and Schlencker, J. (2019). Modular HJS heavy-duty exhaust gas aftertreatment system with independent thermal management for high NOx conversion especially in urban operation. Internationaler Motorenkongress, pp. 221-234. Springer Vieweg, Wiesbaden.

[33] Kirwan, J. E., Quader, A. A. and Grieve, M. J. (2002). Fast start-up on-board gasoline reformer for near zero emissions in spark-ignition engines, SAE Technical Paper (No. 2002-011011).

[34] Hamedi, M. R., Doustdar, O., Tsolakis, A. and Hartland, J. (2018). Thermal energy storage system for efficient diesel exhaust after treatment at low temperatures. Applied Energy, 235, 874-887.

[35] Kovacs, D. et al. (2019). Modeling heavy-duty engine thermal management technologies to meet future cold start requirements. SAE Technical Paper (No. 2019-01-0731).

[36] https://lotusproactive.files.wordpress.com/2013/08/gettingstarted-with-lotus-engine-simulation.pdf. Lotus Engineering, Getting started with Lotus Engine Simulation. (Accessed March 2020).

[37] https://www.lotuscars.com/engineering/engineering-software. Lotus engineering software, Lotus Engine Simulation 2013 version.

[38] Garg, A. et al. (2016). Fuel-efficient exhaust thermal management using cylinder throttling via intake valve closing timing modulation. Proceedings of the Institution of Mechanical Engineers, Part D: Journal of Automobile Engineering, 230(4), 470-478. 
[39] Heywood, J. B. (1988). Internal combustion engine fundamentals. McGraw-Hill Education.

[40] Winterbone, D. E. and Pearson, R. J. (2000). Theory of engine manifold design. Wave action methods for I. C. engines. Professional Engineering Publications.

[41] Watson, N. and Pilley, A. D. (1980). A combustion correlation for diesel engine simulation. SAE Technical Paper (No. 800029).

[42] Sandoval, D. and Heywood, J. B. (2003). An improved friction model for spark-ignition engines. . SAE Technical Paper (No. 2003-01-0725).

[43] Annand, W. J. D. (1963). Heat transfer in the cylinders of reciprocating internal combustion engines. . Proceedings of the Institution of Mechanical Engineers, 177(1), 973-996.

[44] Stanton, D. W. (2013). Systematic development of highly efficient and clean engines to meet future commercial vehicle greenhouse gas regulations. SAE International Journal of Engines, 6(3), 1395-1480.

[45] Ding, C. (2014). Thermal efficiency and emission analysis of advanced thermodynamic strategies in a multi-cylinder diesel engine utilizing valve-train flexibility. PhD Thesis, School of Mechanical Engineering, Purdue University, West Lafayetta, Indiana. 